\title{
Farklı Buğday Genotiplerinin Azot, Fosfor ve Potasyum Kullanım Etkinlikleri
}

\author{
Mehmet ALPASLAN' \\ Geliş Tarihi: 28.05.2001
}

\begin{abstract}
Ozet: Bitkilerde besin maddesi kullanım etkinliği biomas, besin maddesi alımı ve konsantrasyunu gibi bazı faltörlere bă̆lı karmaşık bir sistemdir. Yapilan bir çok çalışmada, genotip ile besin maddesi kullanım etkinliği arasında iliş̧kiler beililenmiştr. Ekmeklik (Triticum aestivum) ve makarnalık (Triticum durum) buğday genotiplerinin azot, fosfor ve potasyum kullanım etkinliklerinin araştinidığı bu deneme 24 adet (19 adet ekmeklik ve 5 adet makarnalık) buğday genotipiyle sera koşullarında yörotölmuştor. Calısmanın sonuçlarına göre, besin maddesı kullanım etkinliği buğday genotiplerine göre farkliliklar göstermiştir. Genellikle makarnalık genotiplerin potasyumu kullanım etkinilikeri ekmeklik genotiplerden daha youksek olmuştur.
\end{abstract}

Anahtar Kelimeler: Bugday, azot, fosfor, potasyum kuilanım ełkinlikleri

\section{Nitrogen, Phosphorus and Potassium Using Efficiency of Wheat Genotypes}

\begin{abstract}
Nutrient efficiency in plants depending on biomass, nutrient uptake and nutrient content is very comlex. Various studies have showed that interactive effects may occur between genotypes and the use efficiencies of the nutrient. In this study effecient use of nitrogen, phosphorus, and potassium was examined in 24 wheat (19 bread and 5 durum) genotypes in a greenhouse experiment. According to the results, use efficiency of the $N, P$ and $K$ by wheal genotypes showed differences between wheat genotypes. Generally, potassium use efficiency of durum wheat genotypes was found to be higher than bread wheat genotypes.
\end{abstract}

Key Words: Wheat, nitrogen, phosphorus, potassium using efficiency

\section{Giriş}

Besin maddesi etkinliği tane arana ve biyomas oluşturmak uzere bitkilerin besin maddesini alım ve kullanim kapasitesi olarak tanımlanmaktadır (Gourley ve ark. 1993). Besin etkinliği çok kompleks olup bașlıca iki temel mekenizmayı içerir. Bunlar, besin maddesi alım etkinliği (kök salgılan ve kơk morfolojisi tarafından kontrol edilen besin maddesi alım mekanizması) ve besin maddesi kullanim etkinliği (her bir gram besin maddesine karşılık üretilen kuru madde)'dir (EI Bassam 1998). Yapilan çeșitli çalışmalarda gunümuzän tahıl genotiplerinin eski genotiplere gore daha youksek arün verdikleri ortaya konulmuştur (Austin 1988, Altin ve Frey 1990, Dambroth ve El Bassam, 1990, Damisch ve Wiber 1991). Genetik olarak geliștirilmiş bitki varyeteleri geleneksel varyetelere göre doğal olarak besin elementlerini alım ve kullanım etkinlikleri bakımından daha başarılı olmaktadır. Besin maddesi etkinliğinin araștırıdığı bir çok çalışmada besin maddesinin tek dözeyi kullanıImıştır. Burada amaç optimum gelişmeyi sağlayan besin maddesi dazeyinde farkli genotiplerin gósterecekleri tepkiyi belirlemektir.

Torkiye' de tarımsal öretim içinde tahılların bayak bir onemi vardır. Ülkemizde ișlenen tarım arazilerinin yaklaşık $\% 80^{\prime}$ inde tahil oretimi yapilmakta, tahil oretiminin yapıldığı alanların yaklaşık \%65' inde de buğday uretimi gerçekleşmektedir (Anonim 1997).

Bu çalışmada Olkemizde yaygın olarak yetiştirilmekte olan ekmeklik ve makarnalık buğday genotipler uç temel makro besin maddesi olan $N_{1}$ P ve $K^{i} u$ kullanım etkinlikleri yönunden karşılaştırılmıştır.

\section{Materyal ve Yöntem}

Araștırma Tesadúf parselleri deneme desenine (Alpaslan ve ark. 1998) göre 4 tekrarlamalı olarak planlanmış ve sera koşullarında $1600 \mathrm{~g}$, toprak alan saksılarda 24 adet buğday (19 adet ekmeklik ve 5 adet makarnalık) genotipi yetiştirilerek yôrütolmûștür. Denemede kullanilan bug̈day genotipleri Çizelge 1 ' de verilmiștir. Her saksıya başlangıçta 18 adet buğday tohumu ekilmiș ve daha sonra saksılarda 12 adet bitki kalacak şekilde seyreltilmiştir. Denemede tekstürü siltti killi tın, $\mathrm{pH}^{\prime}$ sı 8,14; kireç kapsamı \%7,54; EC' si 0,21 dS m-1, organik maddesi $\% 0,80$; toplam $\mathrm{N} \% 0.06$, bitkiye yarayıșli $P$. K kapsamları sırasıyla 5,13 ve $697 \mathrm{mg} \mathrm{kg}^{-1}$ olan toprak kullanılmıştır.

Denemede saksilara $80 \mathrm{mg} \mathrm{kg}^{-1} \mathrm{P}$ ve $100 \mathrm{mg} \mathrm{kg}^{-1} \mathrm{~K}$ $\left(\mathrm{KH}_{2} \mathrm{PO}_{4}\right)$ uygulanmıştır. Azot gübrelemesi ise ekimle birlikte $200 \mathrm{mg} \mathrm{kg}^{-1} \mathrm{~N}$ ve gelișmenin 20 . ganunde $100 \mathrm{mg}$ $\mathrm{kg}^{-1} \mathrm{~N}$ olmak üzere toplam $300 \mathrm{mg} \mathrm{kg}^{-1} \mathrm{~N}$ olacak şekilde yapilmıştır. Bitkiler 52 günlak bir gelișme süresinden sonra hasat edilmiştir. Saf su ile yikanan örnekler $65^{\circ} \mathrm{C}$ ' de kurutulmuş ve kuru ağırlıklan belirlenmiştir. Kuru yakma yónternine göre yakilan bitki örneklerinde toplam $P$ spektrofotometrik olarak (Kitson ve Mellon 1944), toplam K fleymfotometrik olarak belirlenmiştir (Kacar, 1972). Toplam N, Kacar (1972)'de bildirildiği şekilde Kjeldahl yöntemine göre yapılmıștır. Deneme sonunda kuru maddede her bir gram $\mathrm{N}, \mathrm{P}$ ve $\mathrm{K}^{\prime}$ un gram olarak oluşturduğu kuru madde miktarları bulunarak bitkilerin besin maddesi kullanım etkinliği hesaplanmıștır.

Genotipler arası farkılıklan belírlemek amacıyla yeni bir yaklaşım olan EI Bassam $(1998)^{\prime}$ in yöntemi kullanılmıştır. Bu yōnteme göre genotiplerin değerlendirme

\footnotetext{
'Ankara Üniv. Ziraat Fak. Toprak Bölümü-Ankara
} 
Çizelge 1. Denemede kullanilan buğday genotipleri

\begin{tabular}{|c|l|}
\hline Genotip nurnarası & Genotip adı \\
\hline 1 & Gün-91 \\
2 & Ikizce-96 \\
3 & Mizrak-98 \\
4 & Turkmen-98 \\
5 & Uzunyayla-98 \\
6 & Bezostaya \\
7 & Gerek-79 \\
8 & Atay-98 \\
9 & Kuraç-66 \\
10 & Bolal-2973 \\
11 & Kate-A1 \\
12 & Pehlivan \\
13 & Dağdaş \\
14 & Kurkpinar-79 \\
15 & Kirgiz \\
16 & Kutuk \\
17 & Sultan \\
18 & Sivas 111/33 \\
19 & Yektay 406 \\
20 & C- 1252 \\
21 & Kızaltan 40/98 \\
22 & Altın 40-98 \\
23 & Ankara-98 \\
24 & Yilmaz-98 \\
\hline
\end{tabular}

"koyu olanlar makamaltk genotipler

kriterlerine olan tepkimeleri derecelendirilmiş ve sonuçta toplu olarak değerlendirme çizelgesi oluşturulmuştur. Araştırmada kullanilan genotipler değerlendirme kriterleri olarak ele alınan değişim parametreleri bakımından (kuru madde, $N, P, K$ konsantrasyonu ve alimı ile $N, P, K$ kullanım etkinlikleri) yüksek, orta ve dōşok performans duzeylerine göre gruplandırılmıştır. Buna göre, 24 buğday genotipi $3^{\prime}$ e bölanerek ilk $8^{\prime}$ e girenler performansları yäksek olaniarı, ikinci $8^{\prime}$ de yer alan genotipler orta, son $8^{\prime}$ de yer alan buğday genotipleri ise düşak performanslı genotipler olarak değerlendirilmişlerdir.

\section{Bulgular ve Tartışma}

Buğday genotiplerinin kuru ağırlıkları: Araştırmada kullanilan ekmeklik ve makarnalık bư̆gday genotiplerinin oluşturdukları kuru madde miktarları çizelge $2^{\prime}$ de verilmiştir. Oluşturulan kuru madde miktarlarına göre genotiplerin dağılimlan Şekil $1 A^{\prime}$ da gösterilmiștir. Anıtan çizelge ve şekil birlikte incelendiğinde, buğday genotiplerinin oluşturdukları kuru madde miktarları nın farkiliklar gösterdiği anlaşılmaktadır. Burada, ekmeklik çeşitler, makarnalık çeşitlere göre ortalama olarak daha yöksek miktarlarda kuru madde oluşturmuşlardır. En yüksek kuru madde değerini $4.33 \mathrm{~g}$ ile ekmeklik bir çeşit olan Kutluk verirken, bunu yine ekmeklik çeşitlerden Kıraç$66(4.16 \mathrm{~g})$, Gun-91 $(4.15 \mathrm{~g})$ ve Gerek-79 $(4.12 \mathrm{~g})$ izlemişlerdir. Göneş (2000) ve Inal (2001) tarafindan yapılan çalışmalarda, ekmeklik ve makarnalık buğday genotiplerinin yeterli $\mathrm{P}$ düzeylerinde oluşturdukları kuru madde miktarlarında da benzer bulgular saptanmıştır.

Denemede eide edilen kuru madde değerleri en dosşak 8 çeşidin ortalaması $3.01 \mathrm{~g}$ iken en yäksek 8 çeşidin kuru madde ortalamasi $4.07 \mathrm{~g}$ olarak bulunmuştur (Şekil 1A). Makamalık çeşitlerin hepsi daşâk grup içerisinde yer almıştır.

Buğday genotiplerinin azot konsantrasyonu ve azot alımları: Ekmeklik ve makarnalık çeşitlerin azot konsantrasyonları birbirlerine yakin değerler göstermiştir (Çizelge 3). Ekmeklik genotiplerin ortalama N konsantrasyonları $\% 4.72$ olarak belirlenirken, bu değer
Çizelge 2. Buğday genotiplerinin kuru ağırlıkları

\begin{tabular}{|l|c|}
\hline Genotipler & Kuru ağinik g saksi \\
\hline Gün-91 & 4.15 \\
Ikizoe-96 & 3.50 \\
Mizrak-98 & 3.54 \\
Turkmen-98 & 3.99 \\
Uzunyayla-98 & 3.85 \\
Bezostaya & 4.02 \\
Gerek-79 & 4.12 \\
Atay-98 & 3.26 \\
Kurac-66 & 4.16 \\
Bolal-2973 & 3.24 \\
Kate-A1 & 3.60 \\
Pehlivan & 3.66 \\
Dagdas & 3.65 \\
Kirkpınar-79 & 3.11 \\
Kirgiz & 3.92 \\
Kutluk & 4.33 \\
Sultan & 3.64 \\
Sivas 111/33 & 3.70 \\
Yektay 406 & 3.66 \\
G-1252 & 2.85 \\
Kizaitan 40/98 & 2.59 \\
Altın 40-98 & 3.08 \\
Ankara-98 & 3.30 \\
Yilimaz-98 & 2.61 \\
\hline
\end{tabular}

Çizelge 3. Buğday genotiplerinin azot konsantrasyonları ve azot alımları

\begin{tabular}{|l|c|c|}
\hline \multicolumn{1}{|c|}{ Genotipler } & $\begin{array}{c}\text { Nkonsantrasyonu, } \\
\%\end{array}$ & $\begin{array}{c}\text { N alımi, } \\
\text { mg saksi }^{-1}\end{array}$ \\
\hline Gün-91 & 4.998 & 207.4 \\
Ikizce-96 & 4.756 & 166.5 \\
Mizrak-98 & 4.622 & 163.6 \\
Türkmen-98 & 4.760 & 189.9 \\
Uzunyayia-98 & 4.311 & 166.0 \\
Bezostaya & 5.051 & 203.1 \\
Gerek-79 & 4.504 & 185.6 \\
Atay-98 & 4.824 & 157.3 \\
Kiraç-66 & 4.687 & 195.0 \\
Bolal-2973 & 4.585 & 148.6 \\
Kate-A1 & 4.805 & 173.0 \\
Pehlivan & 4.788 & 175.2 \\
Dağdaş & 5.086 & 185.6 \\
Kırkpınar-79 & 4.933 & 153.4 \\
Kırgız & 4.554 & 178.5 \\
Kutluk & 4.951 & 214.4 \\
Sultan & 4.463 & 162.5 \\
Sıvas 111/33 & 4.541 & 168.0 \\
Yektay 406 & 4.377 & 160.2 \\
C-1252 & 4.995 & 142.4 \\
Kızaltan 40/98 & 4.994 & 129.3 \\
Altın 40-98 & 5.315 & 163.7 \\
Ankara-98 & 4.675 & 154.3 \\
Yılimaz-98 & 4.145 & 108.2 \\
\hline
\end{tabular}

makarnalık çeşitlerde \%4.82 olmuştur. Buğday genotiplerinin azot alımları ise farkılıklar gösterip ortalama olarak ekmeklik çeșitlerde $176.52 \mathrm{mg}$ saksi $^{-1}$, makarnalık çeşitlerde ise $139.58 \mathrm{mg} \mathrm{saksi}^{-1}$ olmuştur (Çizeige 3 ).

Bitkiler azot konsantrasyonlan ve azot alımlarına gơre gruplandırildığında Dağdaş, Bezostaya, Gan-91 ve Kutluk çeşitlerinin her ikj parametrede de yukssek grup içerisinde yer aldı̆̆ı görülmektedir (Şekil 1B ve C).

Buğday genotiplerinin fosfor konsantrasyonu ve fosfor alımları: Denemede kullanilan ekmeklik ve makarnalık buğday genotiplerinin $P$ konsantrasyonları ve P alımları çeşitiere göre bôyök farklitiklar göstermiştir (Çizelge 4 ve Şekil 1C). Ekmeklik genotiplerin P konsantrasyonları ortalama $\% 0.322$ olarak bulunurken, makarnalık genotiplerin P konsantrasyonları ortalama 
$\% 0.334$ olmuştur, Buğday genotiplerinin fosfor alımları ise ekmeklik çeşitlerde ortalama $12.04 \mathrm{mg} \mathrm{saks}^{-1}$, makarnalik genotiplerde $9.7 \mathrm{mg}$ saks! ${ }^{-1}$ olarak bulunmuştur.

Ganeș (2000) ve Inal (2001) fosfor uygulamalarına bağlı olarak ekmeklik ve makarnalık buğday genotiplerinin $P$ konsantrasyonları ve $P$ alımiarinda benzer sonuçlar elde etmişlerdir. Derici (1999) ve Öztürk ve ark. (2000) tarafından ekmeklik ve makarnalık buğdaylar lle buniarın değişik genotipleri arasında da fosfor konsantrasyonları açısından farklilıklar olduğu belirlenmiştir.

Bitkiler $P$ konsantrasyonu ve $P$ alımları yönünden gruplandırldığında benzer şekilde Yılmaz-98, Bolal-2923, Sivas-111/33, Mizrak-98 ve Ikizce-96 genotipleri duşuk performansilı grup içerisinde yer almışiardır (Şekil 10 ve E).

Bug̃day genotiplerinin potasyum konsantrasyonu ve potasyum alimiart: Buğday genotiplerinin $K$ konsantrasyonu ve $\mathrm{K}$ alımlan ekmeklik ve makarnalik çeșitlerde farklılıklar göstermiştir (Çizelge 5). Ekmeklik genotipler gerek $\mathrm{K}$ konsantrasyonu gerekse $\mathrm{K}$ alımı yönünden makarnalık çeşitlere göre daha yüksek degerlere ulaşmıştır. Ortalama potasyum konsantrasyonlan ekmeklik çeşitlerde $\% 4,636$, makarnalık çeşitlerde ise ortalarna $\% 3.713$ olurken, $K$ alimları açısından sirasıyla $182.1 \mathrm{mg}$ saksi $^{-1}$ ve $107.5 \mathrm{mg} \mathrm{saksi}^{-1}$ olmuştur (Cizelge 5).

Ekmeklik ve makamalik bugday genotipleri $\mathrm{K}$ konsantrasyonu ve $\mathrm{K}$ alımiarına göre gruplandirıldığında makarnalık çeşitlerin (Ç-1252 hariç) dôşok performanshı grupta yer aldığı görälmektedir (Şekil $2 \mathrm{~A}$ ve $\mathrm{B}$ ).

Buğday genotiplerinin azot, fosfor ve potasyum kullanım etkinlikleri: Ekmeklik ve makarnalık buğday genotiplerinin $N, P$ ve $K$ kullanim etkinlikleri hesaplanmıș ve Çizelge $6^{\prime}$ da toplu olarak verilmiştir. Anilan çizelgenin incelenmesinde de görüleceğl azere genotiplerin besin maddeferini kullanım etkinlikleri oldukça farklilıklar göstermektedir. Bir başka deyișle çeşitlerin azot, fosfor ve potasyumu kulianim yetenekleri farklı olmuștur.

Çeșitler azot, fosfor ve potasyumu kullanim etkinlinliklerine gore gruplandirildiklarinda makamalık çeşitlerin potasyumu azot ve fosfora gore daha etken kullandikları görülmektedir (Şekil 2C, D ve E).

Bitkilerin fosfor kullanim etkinlik değerferi azot ve potasyuma göre belirgin derecede yüksek bulunmuştur (Çizelge 5), Bu durum çeşitlerin genetik potansiyellerinin farklı olmasının bir sonucu olarak açıklanabilir. Inal (2001) yaptığı çalışmada ekmeklik ve makarnalık buğday genotiplerinin agronomik $P$ etkinliği bakımından farklı tepkiler gosterdiğini belirlemiştir.

Araştırmada kullanilan ekmeklik ve makarnalık buğday genotiplerinin değerlendirme kriterlerine göre gostermiş oldukları performansları değerlendirilerek sonuçlar toplu olarak Çizelge $7^{\prime}$ de sunulmuştur. Anılan çızelge incelendiğinde, ekmeklik çeşitıerden Bezostaya ve Gerek-79 çeşitleri değerlendimede kullanilan 10 parametrenin $7^{\prime}$ sinde (kuru madde, $N$ konsantrasyonu ve alımı, $P$ konsantrasyonu ve alimı lie $K$ konsantrasyonu ve alımı) youksek grupta yer almıştır. Bunu Gün-91, Kırgız, Kutluk ve Kıraç-66 çeşitleri izlemektedir.Ekmeklik çeşitlerden Pehlivan tüm parametrelerde orta dozzeyde performans gosterirken, Kate-A1 çeșidi $P$ alıminin dişındaki tüm değerlendirme kriterlerinde yine orta grupta yer almıştır.
Çlzeige 4. Buğday genotipierinin fosfor konsantrasyoniarı ve fosfor alimian

\begin{tabular}{|c|c|c|}
\hline Genotipler & $\begin{array}{c}\text { P konsantrasyonu, } \\
\%\end{array}$ & $\begin{array}{l}\text { P alımi, } \\
\text { mg saiksi }\end{array}$ \\
\hline Gon-91 & 0.320 & 13.3 \\
\hline |kizce-96 & 0.316 & 11.1 \\
\hline Mizrak-98 & D.299 & 10.6 \\
\hline Türkmen-98 & 0.320 & 12.8 \\
\hline Uzunyayla-98 & 0.261 & 10.0 \\
\hline Bezostaya & 0.381 & 15.3 \\
\hline Gerek-79. & 0.352 & 14.5 \\
\hline Atay-98 & 0.347 & 11.3 \\
\hline Kuraç-66 & 0.288 & 11.9 \\
\hline Bolal-2973 & 0.285 & 9.2 \\
\hline Kate-A1 & 0,330 & 11.9 \\
\hline Pehlivan & 0.322 & 11.8 \\
\hline Dağdas & 0.355 & 13.0 \\
\hline Krrkpinar-79 & 0.364 & 113 \\
\hline Kirgiz & 0.340 & 13,3 \\
\hline Kutluk & 0.337 & 14.6 \\
\hline Sultan & 0.310 & 11.3 \\
\hline Sivas $111 / 33$ & 0.270 & 10.0 \\
\hline Yektay 406 & 0.317 & 11.6 \\
\hline C. 1252 & 0.356 & 10.1 \\
\hline Kizaltan 40/98 & 0.343 & 8.9 \\
\hline Altan 40-98 & 0.365 & 11.2 \\
\hline Ankara-98 & 0,340 & 11.2 \\
\hline Yilmaz-98 & 0.265 & 6.9 \\
\hline
\end{tabular}

Cizelge 5. Buğday genotiplerinin potasyum içerikleri ve potasyum alımian

\begin{tabular}{|c|c|c|}
\hline Genotipler & $\begin{array}{c}\text { K konsantrasyonu, } \\
\%\end{array}$ & $\begin{array}{l}\mathrm{K} \text { alimi, } \\
\text { mg saksi }^{-1}\end{array}$ \\
\hline G0n-91 & 4.890 & 202.9 \\
\hline |kizce-96 & 4.904 & 171.6 \\
\hline Mizrak-98 & 4.975 & 176.1 \\
\hline Tarkmen-98 & 4,831 & 191,8 \\
\hline Uzunyayla-98 & 4.901 & 188.7 \\
\hline Bezostaya & 6.159 & 247.6 \\
\hline Gerek-79 & 5.237 & 215.8 \\
\hline Atay-98 & 5.199 & 169,5 \\
\hline Kuraç-66 & 5,400 & 224.6 \\
\hline Bolal-2973 & 5.961 & 193.1 \\
\hline Kate-A1 & 4.528 & 163.0 \\
\hline Pehlivan & 4.644 & 170,0 \\
\hline Dağdaş & 4.991 & 182.2 \\
\hline Kırkpinar-79 & 3.755 & 116.8 \\
\hline Kirgiz & 3.826 & 1500 \\
\hline Kutluk & 4.580 & 198.3 \\
\hline Sultan & 4.391 & 159,8 \\
\hline Sivas $111 / 33$ & 4.909 & 181.6 \\
\hline Yektay 408 & 4.265 & 156.1 \\
\hline C. 1252 & 4.564 & 130.1 \\
\hline Kizaltan 40/98 & 4.031 & 104.4 \\
\hline Altin $\mathbf{4 0 - 9 8}$ & 3.522 & 108.5 \\
\hline Ankara-98 & 3.615 & 120.6 \\
\hline Yilmaz-98 & 2.833 & 73.9 \\
\hline
\end{tabular}

Makarnalık buğday genotiplerinin değerlendirme kriterlerine gore performans duzeyleri genelde ekmeklik çeșitlere göre doşak olmuştur (Çizelge 7). Kızıltan 40/98 ve Yilmaz-98 makarnalik çeşitleri incelenen 7 parametrede doşak grupta yer alırken, bunları ç-1252 6 parametrede ve Altın $40 / 98$ çeșidide 5 parametrede daşak grupta yer alarak izlemişlerdir.

Bu çalıșmanın sonuçlarına göre çeşit seçiminde kriter olabilecek bir sinıflandırma yapıimıştır. Buna göre araştırma koşullarında çeşitlerin göstermiş oldukları performanslara gore uretimde başarıl olunabilecek çeşitlere yonelmede yol gosterebllecektir. Ayrıca araştırma sonuçlari ozellikle tarla koşullarında yapilacak bu tûr çalışmalara kaynak olabilecektir- 

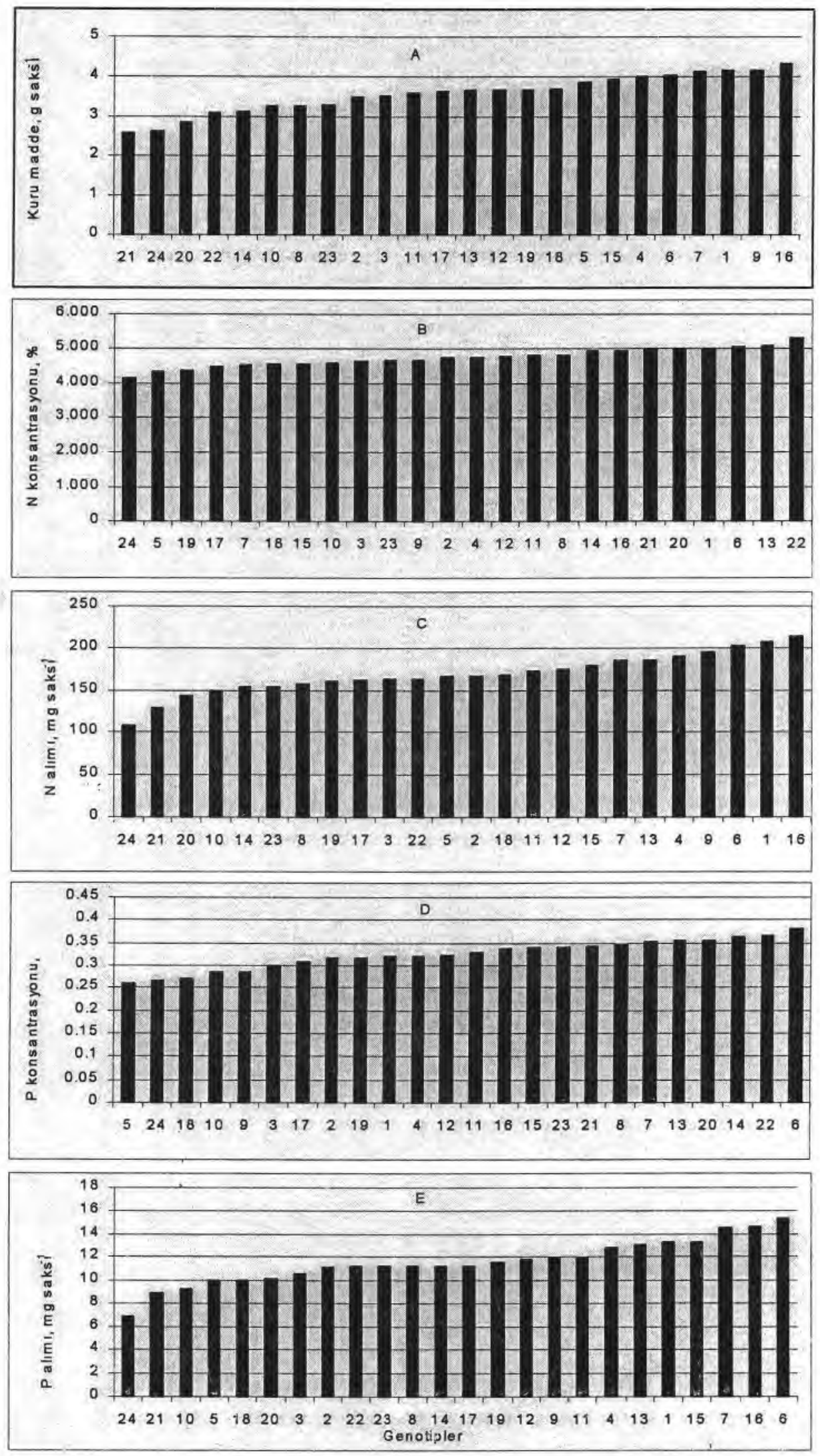

Şekil 1. Buğday genotiplerinin kuru maddeleri $(A), N$ konsantrasyonu $(B), N$ alımı $(C), P$ konsantrasyonu $(D)$ ve $P$ alımı $(E)$ yönünden gruplandırimaları 

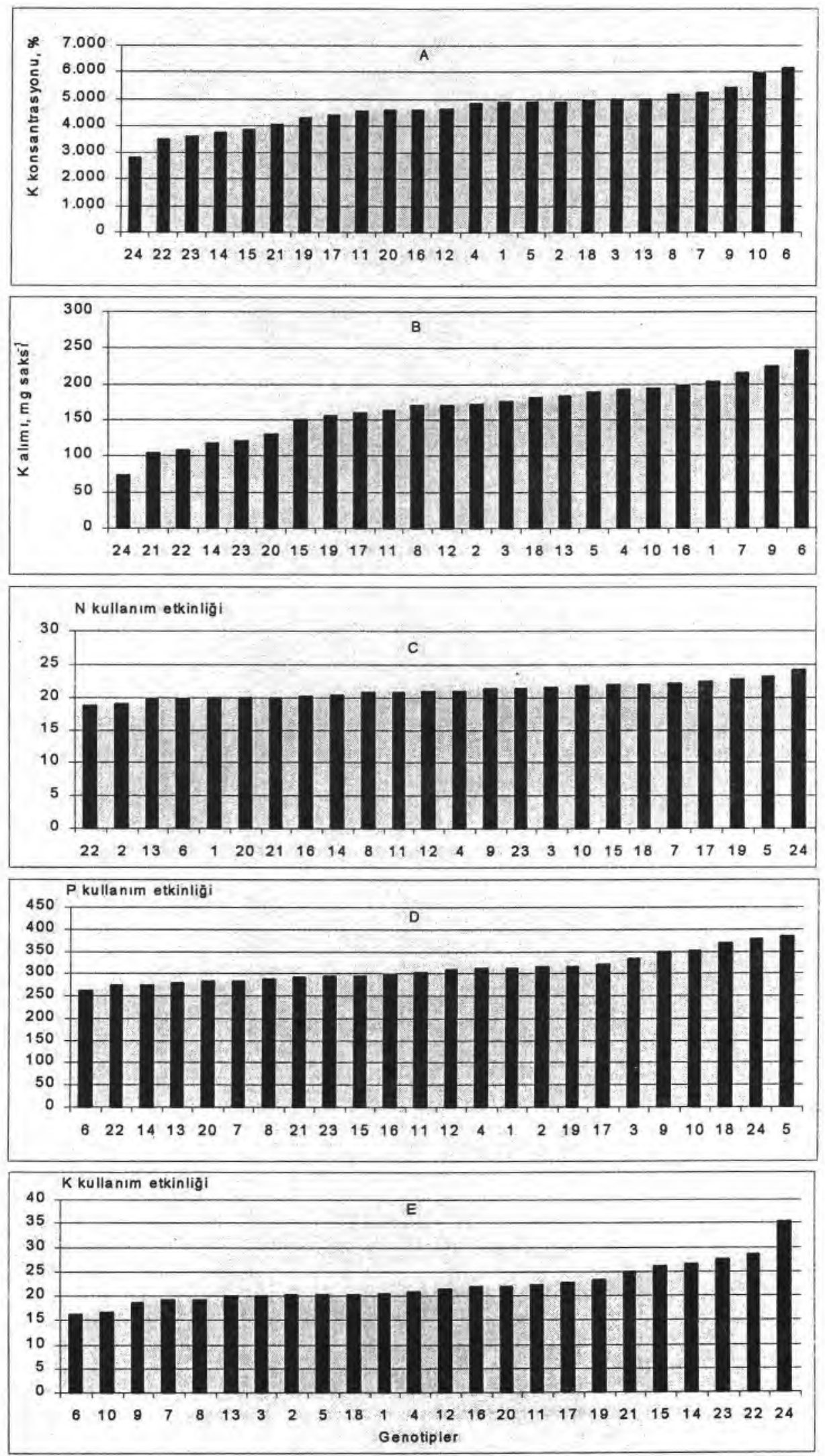

Şekil 2. Buğday genotiplerinin $K$ konsantrasyonu (A), K alımı (B), N kullanım etkinliği (C), $P$ kullanım etkinliği (D) ve K kullanım etkinliği (E) yönünden gruplandırıımaları 
Çizelge 6. Buğday genotiplerinin besin maddesi kullanım etkinlikleri

\begin{tabular}{|l|l|l|l|}
\hline Genotipler & Azot & Fosfor & Potasyum \\
\hline Gun-91 & 20.0 & 312.0 & 20.5 \\
Ikizce-96 & 18.9 & 315.3 & 20.4 \\
Mizrak-98 & 21.6 & 334.0 & 20.1 \\
Türkmen-98 & 21.0 & 311.7 & 20.7 \\
Uzunyayla-98 & 23.2 & 385.0 & 20.4 \\
Bezostaya & 19.8 & 262.7 & 16.2 \\
Gerek-79 & 22.2 & 284.1 & 19.1 \\
Atay-98 & 20.7 & 288.5 & 19.2 \\
Kurac-66 & 21.3 & 349.6 & 18.5 \\
Bolal-2973 & 21.8 & 352.2 & 16.8 \\
Kate-A1 & 20.8 & 302.5 & 22.1 \\
Pehlivan & 20.9 & 310.2 & 21.5 \\
Dağdaş & 19.7 & 280.8 & 20.0 \\
Kirkpınar-79 & 20.3 & 275.2 & 26.6 \\
Kirgız & 22.0 & 294.7 & 26.1 \\
Kutluk & 20.2 & 296.6 & 21.8 \\
Sultan & 22.4 & 322.1 & 22.8 \\
Sivas 111/33 & 22.0 & 370.0 & 20.4 \\
Yektay 406 & 22.8 & 315.5 & 23.4 \\
C-1252 & 20.0 & $\mathbf{2 8 2 . 2}$ & $\mathbf{2 1 . 9}$ \\
Kizaltan 40/98 & 20.0 & 291.0 & 24.8 \\
Altın 40-98 & $\mathbf{1 8 . 8}$ & $\mathbf{2 7 5 . 0}$ & $\mathbf{2 8 . 4}$ \\
Ankara-98 & 21.4 & 294.6 & 27.4 \\
Yilmaz-98 & 24.1 & 378.3 & $\mathbf{3 5 . 3}$ \\
\hline
\end{tabular}

\section{Kaynaklar}

Alpasian, M., A. Güneş ve A. Inal, 1998. Deneme Tekniği. A.O.Ziraat Fakültesi Yayınları: 1501. Ders Kitabı: 455.

Altin, G. N. and K. J. Frey, 1990. Breeding crop varieties for low input. Am. J. Alt. Agric. 4: 53-58.

Anonim, 1997. Tarım İstatistikleri Özeti. DIE. Yayın No: 2137. Ankara.

Austin, R. B. 1988. A different ideocype for each environment.? In: M.L. Jorna \& L.A. J. Sloocmaker (Eds.), Cereal Breeding Related to Integrated Cereal Production. Proceedings of the EUCARPIA conference, pp. 47-60. PUDOC, Wageningen, the Netherlands.

Dambroth, M. and N. El Bassam, 1990. Genotypic variation in palant productivity and consequences for breeding of lowinput cultivars. In: N. El Bassam, M. Dambroth \& B.C. Loughman (Eds.), International Symposium on Genetic Aspects of plant. Mineral Nutrition, pp. 1-7. Kluwer Academic Publishers, the Netherlands.

Damisch, W. and A. Wiberg, 1991. Biomass yield- A topical issue in modern wheat breeding programmes. Plant Breeding 107: 11-17.

Derici, R. 1999. Fosfor eksikliğine dayanıkı (fosfor etkin) buğday genotiplerinin belirlenmesi ve etkinlik mekanizmalarının morfolojik ve fizyolojik açıdan karakterize edilmesi. Tubitak TOGTAG/TARP- 2028 No' lu proje ll.ara rapor.
Çizelge 7. Buğday genotiplerinin performans düzeylerine göre dağılımları

\begin{tabular}{|c|c|c|c|c|}
\hline \multirow[t]{2}{*}{ Genotipler } & \multicolumn{3}{|c|}{ Dozeyler } & \multirow[t]{2}{*}{ Derecesi } \\
\hline & Yoksek & Orta & Daşak & \\
\hline Gün-91 & 5 & 4 & 1 & 4 \\
\hline İkizce-96 & - & 6 & 4 & 24 \\
\hline Mızrak-98 & 2 & 5 & 3 & 18 \\
\hline Torkmen-98 & 4 & 6 & - & 8 \\
\hline Uzunyayla-98 & 4 & 3 & 3 & 9 \\
\hline Bezostaya & 7 & - & 3 & 2 \\
\hline Gerek-79 & 7 & - & 3 & 1 \\
\hline Atay-98 & 2 & 4 & 4 & 19 \\
\hline Kuraç-66 & 5 & 3 & 2 & 5 \\
\hline Bolal-2973 & 4 & $=$ & 6 & 10 \\
\hline Kate-A1 & 1 & 9 & - & 21 \\
\hline Pehlivan & $=$ & 10 & - & 23 \\
\hline Dagdaş & 5 & 2 & 3 & 7 \\
\hline Kırkpınar-79 & 3 & 2 & 5 & 14 \\
\hline Kurgiz & 5 & 2 & 3 & 6 \\
\hline Kutluk & 5 & 4 & 1 & 3 \\
\hline Sultan & 3 & 4 & 3 & 12 \\
\hline Sivas $111 / 33$ & 3 & 4 & 3 & 11 \\
\hline Yektay 406 & 3 & 3 & 4 & 13 \\
\hline C. 1252 & 2 & 2 & 6 & 20 \\
\hline Kizaltan 40/98 & 3 & : & 7 & 16 \\
\hline Altun $40-98$ & 3 & 2 & 5 & 15 \\
\hline Ankara-98 & 1 & 5 & 4 & 22 \\
\hline Yilmaz-98 & 3 & - & 7 & 17 \\
\hline
\end{tabular}

El Bassam, N. 1998. A concept of selection for 'low input' wheat varieties. Euphytica 100: 95-100.

Gourley, C. J. P., D. L. Allan and M. P. Russelle, 1993. Defining phosphorus efficiency in plants. Plant Soil 155/156: 289292.

Güneş, A. 2000. Ekmeklik (T. aestivum) ve makarnal:k (T. durum) buğday genotiplerinin bor alımı uzerine fosforun etkisi. Tarım Bilimleri Dergisi 6 (4): 44-48.

Inal, A. 2001. Fosfor alımı ve fosfor etkinliği yönünden bazı ekmeklik (T. aestivum) ve makarnalık ( $T$. durum) buğday genotipleri arasındaki farklılıkların belirlenmesi. Tarım Bilimleri Dergisi (baskıda).

Kacar, B. 1972. Bitki ve Toprağın Kimyasal Analizleri: II. Bitki Analizieri. A.Ô.Ziraat Fakültesi Yayınlarr: 453. Uygulama Kilavuzu: 155.

Kitson, R. E. and M. G.Mellon, 1944. Colorimetric determination of phosphorus as molybdo-vanadophosphoric acid. Ind. Eng. Chem. Anal. Ed., 16: 379-383.

Öztörk, L., B. Torun, I. Gültekin, C. Çekiç, Z. Keklikçi ve I. Çakmak, 2000. Fosfor eksikliğine dayanıklı buğday genotiplerinin belirlenmesi ve buğdayın fosfor eksikliğinde rol alan mekanizmalarının araștırıması. TARP-2028. Tabitak TARP Simpozyumu Proğram ve Bildiri Özetleri. s. 9-10. 